\title{
A Study on the Role of MOOCs in Computer Basic Teaching in Universities
}

\author{
Bo-Qin LIU ${ }^{1, a}$ and Han-Rong CHEN ${ }^{2, b, *}$ \\ ${ }^{1,2}$ Faculty of Computer and Information Science Southwest University Chongqing, China 400715

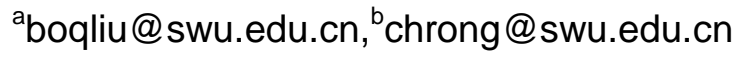

Keywords: MOOC, Basic Computer Science Classroom teaching

\begin{abstract}
MOOC in China is developing rapidly, we will curtain into the university computer basic course teaching. It is found that there are some limitations in the process of computer basic teaching in the university. Through the intervention and guidance of the teacher, the problems and shortcomings brought by the introduction of the curtain teaching can be solved and perfected. The auxiliary function of the curtain teaching can improve the basic teaching of the university quality.
\end{abstract}

\section{Introduction}

With the rapid development of network information technology, advanced science and technology has been applied more and more to university teaching. The development of network technology has led to a great change in the way and way of obtaining knowledge. Especially with the emergence of MOOC, students can systematically learn a course on the network. University computer basic course by the time limit, the class can not be fully in-depth teaching, especially the use of some software, can only talk about some of the most basic operation, not in-depth study of the use of software. MOOC can be a good job to make up for this teaching flaw.

MOOC is an acronym for large-scale open-ended online courses. This term was developed in 2008 by Dave Cormier and Bryan Aexander, which rose rapidly in the United States in 2011 and has had a tremendous impact and far-reaching impact on the current model of higher education. In 2012 the three major MOOC suppliers came into being, Udacity (http://www.udacity.cm), Coursera (http://www.coursera.org), and edX (http: //www.edx .org). After that, whether in Europe or Asia, many universities have launched with the characteristics of the University of MOOC companies and courses.

\section{MOOC Features}

MOOC is an online course that combines distributed learning with open instruction. It is generally a combination of video and handouts, assignments and projects, emphasizing students' active learning and self-organization learning.

MOOC course forms include weekly reading, video and recommended activities, and regularly have test questions to test learners' learning. Some courses will also invite professional leaders in the field of lectures, teaching content has a strong knowledge and forward-looking. We have an online discussion about the course content or a topic, ask yourself questions or ideas, and answer questions from others. Compared with the traditional teaching, MOOC has its own characteristics:

\section{Open course}

The learner only needs to register the account on the MOOC website, set the user name and password to browse the course on the corresponding website. The number of registered courses in a course can reach tens of thousands or even ten thousand people. There is no limit to the registered learner, as long as you can go online regardless of who you can register to study related courses. MOOC is free from the limitations of traditional classroom teaching, breaking the limitations of traditional teaching in time and geography so that learners can learn at the right time and place. 
In order to facilitate learning and improve the speed of network transmission, MOOC teaching video is often divided into ten minutes or smaller fragments. These small pieces of knowledge involved in a single point, a short time, very convenient for learners anytime, anywhere learning. Because the knowledge point is single, so students learn more easily.

\section{Interactivity}

The biggest difference between MOOC and traditional online education is interactivity. Traditional online education course providers do not organize teaching, nor do they give learners an assessment, and learners can not understand their own degree of knowledge. At the same time, there is no communication between learners. Throughout the learning process, the learner is just one person studying. MOOC not only provides resources, but also to achieve the full participation of the teaching process. Learners to complete the work will be published on the Internet, for everyone to discuss, do not understand the problem can also ask the assistant through the network platform.

In addition to the placement, MOOC will provide learners with a course catalog, including course introduction, syllabus, teaching plan schedule, online course video, and so on several parts. In the course of teaching, learners of different regions may have different views on the same question, and learners can talk to each other and communicate with each other. Also, the work of mutual assessment link allows learners to have more understanding of the job, but also deepen the mutual understanding between learners. In the course of the study, each learner must be required to correct a certain number of others. Likewise, there are several different learners in each job. If there is plagiarism, this assignment will not give scoring.

In order to enhance the interaction, to test the learner's learning effect, to further study, MOOC courses using customs clearance mode. The learner can only continue to do the following after having passed the check. For example, when speaking mechanics, the teacher in the video requirements listed in the relevant balance equation. At this time, the explanation is automatically suspended, waiting for the learner to give the correct answer. The computer automatically corrects the learner's input. If the answer is wrong, the system asks the learner to modify the answer until it is correct. If the learner's answer is correct, the teacher's explanation in the video will continue.

\section{Autonomy}

MOOC's entire learning process entirely by the learners themselves to grasp, what time, what location, how to learn, all by the learners themselves to complete. Although MOOC teaching takes into account the difficulties of learners in the learning process, using the combined model, the whole process is completed step by step. However, the learner's own attitudes and active participation are very important. Learners need to solve their own difficulties in the learning process and complete the entire course of learning requirements. If the learners encounter difficulties to give up halfway, the entire course of study will not be able to continue.

For example, in this semester, there were 45 students enrolled in the MOOC program. During the test, the number of students was greatly reduced. Only 20 people participated in the test. Only 9 people took the exam. Of course, these nine people have passed the exam. Afterwards, we did a simple survey of students who did not take the exam or exam. One of the most important reasons why most of the classmates did not end up was that the chosen course was difficult to choose, and did not take into account the knowledge background involved in the course of the course, but simply chose the course that I liked. There are some students to give up because the study of the course is not as simple as imagination, need to spend more time to understand and master. A small number of students feel that the course is lack of realism, no learning atmosphere, the total feeling is a person to learn again, for the online discussion of the learners feel strange, communication blocked, do not want to continue to learn.

This is also one of the reasons for the implementation of MOOC blocked. MOOC platform, the number of registered a lot, but the number of people who passed the exam rarely. If you stay in the registrant, this should be the future of MOOC to consider the top priority. 


\section{MOOC status in China}

Since the emergence of C class, China's colleges and universities have been very concerned about it, thinking about its significance and its impact on the current higher education system. In 2013, Peking University, Tsinghua University and edX signed, Fudan University, Shanghai Jiaotong University and Coursera alliance, and National Defense University of Science and Technology began to build their own MOOC. 2014 China University MOOC platform on the line, more colleges and universities began to use this platform to show the results of MOOC construction, the university students have registered learning related courses. At present, China has at least 32 colleges and universities to carry out MOOC teaching.

By the end of March 2015, the program announced by the Chinese University MOOC platform has reached 320, including computer, economic management, psychology, foreign language, literary history, art design, engineering , Science, life sciences, philosophy, law and education and teaching, is currently the most comprehensive curriculum of the most comprehensive platform. EdX platform Tsinghua University, Peking University courses accumulated 33, Coursera platform Peking University, Shanghai Jiaotong University, Fudan University, Xi'an Jiaotong University courses a total of 47, Tsinghua school online on the 10 domestic universities 102 courses, good university online notice 67 , all accumulated about 450 courses, the development is very fast.

\section{The Limitations of MOOC 's Computer Basic Teaching in Universities}

MOOC in the teaching of colleges and universities have been more and more widely used. Our semester also introduced MOOC in the process of university computer basic teaching. In the use of MOOC process, we also found some of its limitations.

\section{It Can not be Combined with Professional Characteristics to Learn Related Courses}

Any course requires learners to have the necessary professional background knowledge, requiring learners to have a certain understanding and thinking ability. University Computer Foundation This course requires students to master the basic knowledge and skills in the computer field, but also requires students to apply the skills of computers to their respective fields of expertise. Because of limited hours, part of the theoretical knowledge of learning and part of the software needs to use MOOC to complete, but the starting point of MOOC is all students are the same, regardless of knowledge background or professional background are the same. Moreover, MOOC eventually to achieve the goal of teaching is completely consistent, it is impossible according to the different professional adjustment of the corresponding teaching objectives.

For example, for the use of EXCEL software, teachers of professional requirements in EXCEL can handle more than 50 students in the data, according to the test results to analyze the learner's learning situation, can use EXCEL query function to quickly find student-related information. For non-normal students, ask them to use their own professional EXCEL. Science students require the professional experimental data can be analyzed in EXCEL and according to the analysis results or experimental data mapping. Therefore, in the use of EXCEL software, we will be for different professional students to make the appropriate adjustments, given different teaching objectives and teaching methods. MOOC teaching process can not be combined with the learner's own professional background of the teaching objectives of the appropriate adjustments.

\section{In the Teaching Process Can not be in-Depth Interaction}

MOOC platform interaction has been much stronger than the traditional network courses, but MOOC content and interactive system is separated. Because of technical problems, MOOC in the degree of knowledge of learners to master the use of multiple choice questions and numerical input questions, there is no way to deal with the topic. Learners in the test after the end of the information can only be right and wrong, for the wrong where they have to find a solution. Although the learner can ask questions through the discussion area, but this problem is not really solve sometimes even the learners themselves can not judge. Especially in the use of the software, learners use words to express their 
own operations may ignore some of the operational details. For example, in EXCEL advanced filtering, advanced filtering is the most important condition input, as long as the conditions are entered correctly can get the correct screening results. However, many students in the input conditions did not enter the English input method, but in the Chinese input method to complete, which led to the input results are correct, but EXCEL can not identify the correct conditions, not the correct screening results, the system Do not report any mistakes. Most students in the description of this problem did not explain their input method state, and even some students can not distinguish their English input method and the Chinese input method, simply think that can enter the English alphabet is the English input method state.

MOOC can not achieve the interaction between teachers and students in the classroom. In the classroom teaching, the teacher can ask questions or students face to find the problem, to lift the students doubts. In the MOOC teaching process, the teacher is facing the cold camera. This face in the classroom teaching teachers and students in the face of the exchange in the MOOC is never able to do.

\section{Lack of Emotional Communication}

MOOC teaching process without emotional communication, learners learn completely rely on their own stick to it. Any learning will encounter difficulties, there will be to give up the idea. In the classroom teaching, the teacher's encouragement and the help of students, the difficulties encountered by the students will continue to learn, and MOOC teaching is difficult to do this. Due to the introduction, MOOC course enrolls a large number of people who can really pass the exam to get the certificate very few people.

\section{The Role of MOOC in Basic Computer Teaching in Universities}

Although there are some limitations in MOOC teaching, it is necessary to make full use of MOOC and play its advantages, solve and improve the problems and shortcomings brought about by MOOC, and play an auxiliary role of MOOC, which will promote the teaching reform in colleges and universities.

\section{MOOC has a Guiding Role in Student Learning}

We in the classroom teaching process, can not face to, especially the software is very simple to explain. Teachers in the classroom only need to explain the relevant software according to the professional production of the software, the layout of related operations. After class, students can choose according to their own computer level and interest in the MOOC to choose which software to continue in-depth study.

So learning the MOOC course is not the ultimate goal. Through the MOOC study, so that students can really study a certain area of the computer, and this area with their own professional combination.

\section{MOOC Changes the Way Students Learn}

Most of our students only come into contact with classroom teaching, little contact for online teaching. The emergence of MOOC allows students to learn through a variety of ways, but also with the same interests of people who work together. In this way, for the diversified development of students helpful, the use of student team spirit training.

When we use the MOOC to guide students to ask two or more students to register the same course at the same time, we can form a learning atmosphere so that students can adapt to the network teaching method as soon as possible. The teacher will take this into account when arranging homework, and the usual assignment requires more than one person to complete.

Through the study of MOOC, teachers want students to understand that there are many ways to learn, there are a variety of ways to solve the problem. Teamwork is very important and students should learn to work together. 


\section{MOOC is a Supplement to Classroom Teaching}

Our class teaching is 45 minutes a lesson, after class can not repeat the contents of the class once again. For poor computer students, we recommend using MOOC to register for the same content. MOOC learning can be repeated to listen to the same lesson, which for our classroom teaching is a good supplement.

\section{Conclusion}

As a teacher, we should make full use of the MOOC learning platform to guide students to learn MOOC courses. We play the advantages of traditional classroom education, to learn the advantages of MOOC, give full play to MOOC as our university computer basic education auxiliary role.

\section{Acknowledgment}

This work was jointly supported by for the Education research project of Southwest University (NO. 20710110).

\section{References}

[1] Liu Wenhua,,Wang Xiaolei and Han Xianjie, "Effects of MOOCs on Traditional Education and Its Development Countermeasures,” Journal of Anhui Agri. Sci. 2016,44(3) :326-328

[2] Wang xiao and Wang zhiquan, "Research on the Teaching Mode of Chinese Universities in the Background of MOOC”, Journal of National Academy of Education Administration,2015, pp.41-45.

[3] Wang Yingjie,Feng ce and Nie yunjig,"Situation Analysis of MOOC in China Higher Education and Countermeasure”, China's audio education,No.341,2015,pp.80-84.

[4] Zhao Yancheng,Sun qiuhua and Jiang Haili,’The Comparison and Countermeasure about MOOCs and Traditional Classroom Education”,Heilongjiang Researches on Higher Education, No.8,2016.

[5] Deng Hongzhong, Li Mengjun, Chi Yan and Tan Siyu, “Courses and knowledge system network modeling in MOOC”, Course Education Research, July,2013,pp.5-7 